\section{OPEN ACCESS}

Edited by:

Maurizio Sanguinetti,

Catholic University of the Sacred

Heart, Italy

Reviewed by:

Ludmila Baltazar,

Federal University of Minas

Gerais, Brazi

Michael S. Price,

Liberty University, United States

*Correspondence:

Maria José Soares Mendes Giannini

gianninimj@gmail.com

Specialty section:

This article was submitted to

Fungal Pathogenesis,

a section of the journal

Frontiers in Cellular and Infection

Microbiology

Received: 25 September 2019

Accepted: 25 November 2019

Published: 06 December 2019

Citation:

Singulani JL, Galeane MC, Ramos

MD, Gomes PC, dos Santos CT, de Souza BM, Palma MS, Fusco Almeida AM and Mendes Giannini MJS (2019)

Antifungal Activity, Toxicity, and Membranolytic Action of a

Mastoparan Analog Peptide.

Front. Cell. Infect. Microbiol. 9:419.

doi: 10.3389/fcimb.2019.00419

\title{
Antifungal Activity, Toxicity, and Membranolytic Action of a Mastoparan Analog Peptide
}

\begin{abstract}
Junya de Lacorte Singulani ${ }^{1}$, Mariana Cristina Galeane ${ }^{1}$, Marina Dorisse Ramos ${ }^{1}$, Paulo César Gomes ${ }^{1}$, Claudia Tavares dos Santos ${ }^{1}$, Bibiana Monson de Souza ${ }^{2}$, Mario Sergio Palma ${ }^{2}$, Ana Marisa Fusco Almeida ${ }^{1}$ and Maria José Soares Mendes Giannini ${ }^{{ }^{*}}$
\end{abstract}

\footnotetext{
${ }^{1}$ Department of Clinical Analysis, School of Pharmaceutical Sciences, São Paulo State University-UNESP, Araraquara, Brazil, ${ }^{2}$ Department of Biology, Center for the Study of Social Insects, Institute of Biosciences, São Paulo State University-UNESP, Rio Claro, Brazil
}

Invasive fungal infections, such as cryptococcosis and paracoccidioidomycosis are associated with significant rates of morbidity and mortality. Cryptococcosis, caused by Cryptococcus neoformans, is distributed worldwide and has received much attention as a common complication in patients with HIV. Invasive fungal infections are usually treated with a combination of amphotericin B and azoles. In addition, 5-fluorocytosine (5-FC) is applied in cryptococcosis, specifically to treat central nervous system infection. However, host toxicity, high cost, emerging number of resistant strains, and difficulty in developing new selective antifungals pose challenges. The need for new antifungals has therefore prompted a screen for inhibitory peptides, which have multiple mechanisms of action. The honeycomb moth Galleria mellonella has been widely used as a model system for evaluating efficacy of antifungal agents. In this study, a peptide analog from the mastoparan class of wasps (MK58911) was tested against Cryptococcus spp. and Paracoccidioides spp. In addition, peptide toxicity tests on lung fibroblasts (MRC5) and glioblastoma cells (U87) were performed. Subsequent tests related to drug interaction and mechanism of action were also performed, and efficacy and toxicity of the peptide were evaluated in vivo using the $G$. mellonella model. Our results reveal promising activity of the peptide, with an MIC in the range of $7.8-31.2 \mu \mathrm{g} / \mathrm{mL}$, and low toxicity in MRC and U87 cells $\left(\mathrm{IC}_{50}>500 \mu \mathrm{g} / \mathrm{mL}\right)$. Taken together, these results demonstrate that MK58911 is highly toxic in fungal cells, but not mammalian cells $(\mathrm{SI}>16)$. The mechanism of toxicity involved disruption of the plasma membrane, leading to death of the fungus mainly by necrosis. In addition, no interaction with the drugs amphotericin B and fluconazole was found either in vitro or in vivo. Finally, the peptide showed no toxic effects on G. mellonella, and significantly enhanced survival rates of larvae infected with $C$. neoformans. Although not statistically significant, treatment of larvae with all doses of MK58911 showed a similar trend in decreasing the fungal burden of larvae. These effects were independent of any immunomodulatory activity. Overall, these results present a peptide with potential for use as a new antifungal drug to treat systemic mycoses.

Keywords: invasive fungal infections, antifungal, cell membrane, invertebrate models, antimicrobial peptide 


\section{INTRODUCTION}

Infections caused by fungi have increased dramatically in recent decades, and are associated with significant rates of morbidity and mortality (Thompson et al., 2016). In addition, an increase in the number of immunocompromised patients (transplant recipients, individuals infected with human immunodeficiency virus (HIV), and individuals with cancer), as well as geoclimatic changes, have led to more serious fungal infections (Brown et al., 2012; Armstrong-James et al., 2014). In this context, the systemic mycoses caused by Cryptococcus spp. and by dimorphic fungi, such as Paracoccidioides spp. have been recognized as a growing problem for human health (Thompson et al., 2016).

Cryptococcus neoformans and C. gattii are two etiological agents of cryptococcosis, estimated to be responsible for 278,000 of infections and 181,000 deaths annually worldwide. Cryptococcosis in particular, which is caused by C. neoformans and has a worldwide distribution, has received great attention as a common complication in patients with HIV (Rajasingham et al., 2017). Additionally, Paracocciodioides brasiliensis and P. lutzii are responsible for paracoccidioidomycosis, which is an endemic mycosis in South and Central America (Shikanai-Yasuda et al., 2006; Arantes et al., 2016).

Treatment of mild to moderate cryptococcosis is usually done with the administration of fluconazole and severe cases including cryptococcal meningitis, are treated with amphotericin B combined with 5-fluorocytosine (5-FC) or fluconazole (Mourad and Perfect, 2018). On the other hand, patients with the paracoccidiodomycosis are more commonly treated with amphotericin $\mathrm{B}$, itraconazole and cotrimoxazole (sulfamethoxazole/trimethoprim combination) (ShikanaiYasuda et al., 2017). Recent strategies, such as immunotherapy (interleukins, peptide P10 and monoclonal antibodies against virulence factors), new compounds (APX001, AR-12, T-2307, VT1129, VT1598, and natural products) and repurposing drugs (sertraline, tamoxifen, and tacrolimus) have been evaluated in Cryptococcus and Paracoccidioides infections (de Oliveira et al., 2015; Mourad and Perfect, 2018). Amphotericin B and azoles act on the fungal cell membrane, either by disrupting it or by inhibiting sterol synthesis, whereas 5-fluorocytosine (5-FC) inhibits the nucleic acid synthesis of fungal cell (Scorzoni et al., 2017). However, high systemic toxicity and development of resistance are major problems associated with the clinical use of amphotericin B, azoles, and 5-FC.

In addition, because fungal cells are eukaryotic, developing selective antifungal agents is difficult (Perfect, 2017). Consequently, there has been a marked decline in the development of new antifungals, posing a great challenge to modern medicine. The last antifungals developed were the echinocandins, which function by inhibiting glucan synthesis in the cell wall (Prasad et al., 2016; Scorzoni et al., 2017). However, there is an increasing number of resistant isolates also to this drug class, which can occur many ways, including mutations of three genes FKS1, FKS2, and FKS3. These mutations result in amino acid substitutions and consequently, in different phenotypes of glucan synthase that alter the drug-target interactions (Garcia-Effron et al., 2009; Perlin, 2015). Moreover,
C. neoformans is intrinsically resistant to echinocandins and the efficacy of these antifungal agents is questionable against dimorphic fungi (Denning, 2002). Thus, there is a great need to develop new classes of antifungal agents with good action against these fungi and minimal side effects. In this context, the identification of antifungal peptides can be one of the useful strategies for this task.

Antimicrobial peptides (AMPs) are important molecules found in nature. These components act as a first line of defense to combat pathogens, and have extensive biological activities, such as anti-inflammatory properties and a broad spectrum of activity against Gram-positive and Gram-negative bacteria, fungi, viruses, and tumor cells (da Costa et al., 2015; Wang et al., 2016). AMPs are unique in that they have multiple targets and mechanisms of action, which is useful for decreasing the emerging threat of multidrug-resistant strains (Zaiou, 2007; Yount and Yeaman, 2012; Haney et al., 2017; Kang et al., 2017).

AMPs of the mastoparan class are isolated from social wasp venom and are composed of polycationic peptides with 14 amino acid residues and an amidated C-terminus. They contain 2-4 lysine residues, and have a positive net charge and an alphahelical conformation (Rangel et al., 2011; Silva et al., 2017). Some mastoparan peptides have been well-studied and are known to possess antifungal activity (Silva et al., 2017). These mastoparan AMPs may act by altering membrane permeability or by directly forming pores in the membrane (Choi and Lee, 2014; Rautenbach et al., 2016).

Several methods have been tested for evaluating efficacy and safety of new drugs, including antifungals. In order to avoid or replace animal experiments, mini-hosts have emerged as an alternative system for the study of fungal diseases, and for testing chemical libraries to discover new antifungals. These organisms are more ethically suitable, less expensive, and easier to use compared to mammals. The use of invertebrate animals, such as the honeycomb moth Galleria mellonella, is increasing, especially in the study of systemic mycoses (Kavanagh and Sheehan, 2018; Singulani et al., 2018).

G. mellonella is a moth that feeds on honey, pollen, and beeswax. The viability of its larvae can easily be verified by observing movement and melanization induced in response to infection (Fuchs et al., 2010; Desalermos et al., 2012). The virulence of different fungi, including Paracoccidioides and Cryptococcus species (Mylonakis et al., 2005; Thomaz et al., 2013; Scorzoni et al., 2015; de Lacorte Singulani et al., 2016; SangalliLeite et al., 2016; Palanco et al., 2017) has been successfully studied in G. mellonella. In addition, the effect of azoles and amphotericin B, as well as natural products, have been evaluated in this model (Scorzoni et al., 2013; Favre-Godal et al., 2014; de Lacorte Singulani et al., 2016).

The aim of the present study was to evaluate the in vitro antifungal activity of a mastoparan analog against Cryptococcus and Paracoccidioides species, as well as to determine its toxicity on lung and neural cells. In addition, the mechanism of action and in vivo potency of the peptide were evaluated through flow cytometry assays and in the G. mellonella model, respectively. 


\section{MATERIALS AND METHODS}

\section{Fungi}

Fungal strains used in this study were C. neoformans ATCC 90112, C. gattii ATCC 56990, P. brasiliensis S1 isolate Pb18 (Pb18-chronic PCM/São Paulo, Brazil), and P. lutzii Pb01like strain ATCC MYA-826 (acute PCM/Goiânia, Brazil), which was obtained from the collection of the Laboratory of Clinical Mycology, Faculty of Pharmaceutical Sciences of UNESP, Araraquara (Brazil). Cryptococcus species were maintained in Sabouraud dextrose agar at $30^{\circ} \mathrm{C}$ for $48 \mathrm{~h}$ and Paracoccidioides species were maintained in Fava-Netto agar at $37^{\circ} \mathrm{C}$ for 4 days. Biosafety Level 2 protocols were used in experiments with these fungi.

\section{Peptide}

The mastoparan analog peptide (MK58911) used in this study was previously engineered and synthesized according to Souza et al. (2015). The number 58911 in its name indicates the position of lysine residues in the sequence INWLKIAKKVKGML- $\mathrm{NH}_{2}$. The peptide was solubilized in sterile water to prepare the stock solution.

\section{Microdilution Susceptibility Test}

A microdilution susceptibility test was performed to analyze the minimal inhibitory concentration (MIC) of peptide MK58911, which means the minimum concentration of a compound capable of inhibiting microorganism growth. The assay was conducted according to CLSI M27-A3 method (2008), using an inoculum of $2.5 \times 10^{3}$ cells $/ \mathrm{mL}$ in RPMI-1640 medium (Sigma-Aldrich) supplemented with $0.03 \%(w / v)$ L-glutamine and $2 \%(\mathrm{w} / \mathrm{v})$ glucose, and buffered to $\mathrm{pH} 7.0$ with $0.165 \mathrm{M}$ 4-morpholinopropanesulfonic acid, and evaluated in 96-well microplates. For Paracoccidioides species, some modifications were made according to de Paula E Silva et al. (2013). Serial 2 -fold dilutions of the peptide were prepared to obtain final concentrations ranged from 0.48 to $250 \mu \mathrm{g} / \mathrm{mL}$. Amphotericin B $\quad(0.016-8 \mu \mathrm{g} / \mathrm{mL})$, fluconazole $(0.063-32 \mu \mathrm{g} / \mathrm{mL})$, and itraconazole $(0.016-8 \mu \mathrm{g} / \mathrm{mL})$ were used as controls. For Cryptococcus species, the plates were incubated at $37^{\circ} \mathrm{C}$ with agitation (150 rpm) for $48 \mathrm{~h}$ and fungal growth was visually verified. For Paracoccidioides species, plates were incubated at $37^{\circ} \mathrm{C}$ with agitation (150 rpm) for $72 \mathrm{~h}$ and fungal growth was determined by measuring absorbance at $570-600 \mathrm{~nm}$ using the indicator Alamar Blue (BioSource International). The MIC value was determined for each fungus species. Candida albicans ATCC 90028 was used as reference strain for quality control of the susceptibility tests.

\section{Cytotoxicity Test}

Cytotoxic activity was evaluated in an MRC5 cell line (lung fibroblasts) and U87 cell line (glioblastoma), which were obtained from Banco de Células do Rio de Janeiro (BCRJ Federal University of Rio de Janeiro, Brazil). The cells were cultured in Dulbecco's high glucose Modified Eagle Medium (DMEM; Gibco; Thermo Fisher Scientific) supplemented with $10 \%$ fetal bovine serum (FBS) and were incubated at $37^{\circ} \mathrm{C}$ with $5 \% \mathrm{CO}_{2}$. The experiment was performed using 96-well plates with $5 \times$
$10^{4}$ cells/well, and cells were incubated at $37^{\circ} \mathrm{C}$ with $5 \% \mathrm{CO}_{2}$ for $24 \mathrm{~h}$ for monolayer formation to occur. Serial 2-fold dilutions of the peptide were prepared to obtain final concentrations ranged from 0.96 to $500 \mu \mathrm{g} / \mathrm{mL}$. The plates were incubated at $37^{\circ} \mathrm{C}$ for $24 \mathrm{~h}$ and cell viability was evaluated by measuring absorbance at $570-600 \mathrm{~nm}$ using the indicator resazurin at a concentration of $0.01 \%$. The half maximal inhibitory concentration $\left(\mathrm{IC}_{50}\right)$ was determined and the selective index (SI) of the peptide was calculated according to the formula:

$$
\mathrm{SI}=\frac{\mathrm{IC}_{50}}{\mathrm{MIC}}
$$

\section{Checkerboard Test}

Two different combinations of peptide and standard drug were tested: MK58911 + amphotericin B and MK58911 + fluconazole. C. neoformans was selected for this test and for subsequent experiments (mechanism of action and Galleria mellonella model system) because it causes the highest incidence of systemic mycoses worldwide (mainly in HIV patients) compared to other fungi evaluated in this study (Tenor et al., 2015). $2.5 \times 10^{3}$ cells $/ \mathrm{mL}$ were inoculated and MK58911 concentration ranged from 1.95 to $250 \mu \mathrm{g} / \mathrm{mL}$. Amphotericin $\mathrm{B}$ and fluconazole were diluted in RPMI 1640 (Sigma-Aldrich) using the same concentrations as the susceptibility test. The plates were incubated at $37^{\circ} \mathrm{C}$ for $48 \mathrm{~h}$ and fungal growth was visually verified. Subsequently, the interaction coefficient was evaluated using the fractional inhibitory concentration (FIC) according to formula:

$$
\begin{aligned}
\mathrm{FIC} & =\left(\frac{\text { MIC MK58911 in combination }}{\text { MIC MK58911 alone }}\right) \\
& +\left(\frac{\text { MIC FLU or AMB in combination }}{\text { MIC FLU or AMB alone }}\right)
\end{aligned}
$$

The interaction between the agents was defined as follows: synergistic if FIC $\leq 0.5$; indifferent if FIC $>0.5$ and $\leq 4$; and antagonistic if FIC $>4$ (Reichert-Lima et al., 2016).

\section{Propidium lodide Influx}

One hundred microliters of a suspension of $C$. neoformans cells $\left(1 \times 10^{6}\right.$ cells $\left./ \mathrm{mL}\right)$ in RPMI medium were treated with $100 \mu \mathrm{L}$ of MK58911 peptide in the following concentrations: MIC, $0.5 \times$ $\mathrm{MIC}$, and $2 \times$ MIC. Amphotericin B and fluconazole were used as controls at MIC. The plate was incubated for $4 \mathrm{~h}$ or $24 \mathrm{~h}$ at $37^{\circ} \mathrm{C}$ with constant shaking (150 rpm). Subsequently, propidium iodide $(10 \mu \mathrm{g} / \mathrm{mL})$ was added to wells and the plate was incubated for $5 \mathrm{~min}$ at room temperature in the dark. The cells were analyzed by flow cytometry (BD FACSCanto). Ten microliters of calcofluor white $(50 \mu \mathrm{g} / \mathrm{mL})$ were added and images were captured using the automated microscope IN Cell Analyzer 2000 (GE Healthcare).

\section{Annexin Staining}

The exposure of C. neoformans to MK58911 was performed as previously described for propidium iodide influx. 


\section{Detection of Reactive Oxygen Species (ROS) by Dichlorofluorescin Diacetate}

The exposure of C. neoformans to MK58911 was performed as previously described for propidium iodide influx.

\section{Efficacy and Toxicity in G. mellonella Model} Larvae $(0.15-0.20 \mathrm{~g})$ without dark spots were selected and maintained in Petri dishes ( $n=8-10$ for each group) in the dark at $37^{\circ} \mathrm{C}$ the night before experiments. For efficacy assays, larvae were inoculated with $10 \mu \mathrm{L}$ of $1 \times 10^{5}$ cells/larvae of C. neoformans yeast suspension prepared in PBS with $20 \mathrm{mg} / \mathrm{L}$ ampicillin. After an hour of infection, larvae were inoculated with $10 \mu \mathrm{L}$ of MK58911 at a concentration of 10,50 , or $100 \mathrm{mg} / \mathrm{Kg}$, or with only PBS as a control. For experiments of treatment combinations (MK58911 + amphotericin B and MK58911 + fluconazole), $5 \mu \mathrm{L}$ of each of the solutions were inoculated, resulting in a final dose of $4 \mathrm{mg} / \mathrm{Kg}$ for amphotericin B and $10 \mathrm{mg} / \mathrm{Kg}$ for MK58911 and fluconazole. Yeast suspensions and treatments were injected in the back left and right proleg of the larvae, respectively, which were previously cleaned with $70 \%$ alcohol. For toxicity assays, non-infected larvae were injected with the same doses of peptide. In addition, a group of non-infected larvae inoculated with PBS was used as a control in both assays. The viability of larvae was evaluated daily for 5 days.

\section{Fungal Burden}

G. mellonella larvae ( $n=5$ for each group) were infected with $C$. neoformans $\left(1 \times 10^{5}\right.$ cells/larvae $)$ and treated with MK58911 at 10,50 , or $100 \mathrm{mg} / \mathrm{Kg}$ or amphotericin B at $4 \mathrm{mg} / \mathrm{Kg}$. A group of infected non-treated larvae was used as a control. Larvae were incubated at $37^{\circ} \mathrm{C}$ for $24 \mathrm{~h}$. Subsequently, larvae from each group were surface sterilized in $70 \%$ ethanol, cut into small pieces using a scalpel, and suspended in $1 \mathrm{~mL}$ of PBS with $20 \mathrm{mg} / \mathrm{L}$ ampicillin. Tissues were transferred to conical tubes with glass beads and homogenized using a vortex mixer (Norte Científica). Each sample was diluted $100 \times$ or $10 \times$ in PBS, and $100 \mu \mathrm{L}$ of the resulting dilution was plated on Sabouraud dextrose agar supplemented with $0.1 \%$ chloramphenicol. The plates were incubated at $37^{\circ} \mathrm{C}$ for $48 \mathrm{~h}$ and colony-forming units (CFU) were counted.

\section{Haemocyte Density}

G. mellonella larvae ( $n=5$ for each group) were injected with MK58911 at 10, 50, or $100 \mathrm{mg} / \mathrm{Kg}$ and incubated at $37^{\circ} \mathrm{C}$ for 4 or $24 \mathrm{~h}$. Larvae inoculated with $\mathrm{PBS}$ were used as a control. Subsequently, the hemolymph was collected and diluted 1:20 in cold PBS. The haemocyte were counted using a Neubauer hemocytometer under a brightfield microscope.

\section{Statistical Analysis}

All data in this study are representative of at least three independent experiments with mean \pm S.D. Graphs and statistical analyses were performed with GraphPrism 5.0 (GraphPad Software Inc., La Jolla, CA). The data from mechanism of action studies, fungal burden, and haemocyte density were compared using a one-way analysis of variance (ANOVA) followed by Dunnett's test $(P<$ 0.05). The data from in vivo efficacy studies were plotted as Kaplan-Meier survival curves and compared using log-rank tests.

\section{RESULTS}

\section{MK58911 Shows in vitro Activity Against Fungi Causing Systemic Mycoses and Has Low Toxicity in Mammalian Cells}

Our results demonstrated that the peptide MK58911 had activity in the following order: $P$. brasiliensis $>P$. lutzii $=C$. gattii $>$ C. neoformans, with MIC values ranging from 7.8 to $31.2 \mu \mathrm{g} / \mathrm{mL}$ (Table 1). In addition, MK58911 was not toxic in lung fibroblasts (MRC5) and glioblastoma cells (U87) at tested concentrations, and a high $\mathrm{IC}_{50}$ of $>500 \mu \mathrm{g} / \mathrm{mL}$ was observed in both mammalian cells. From these data, the selectivity index (SI), which consists of the ratio between the $\mathrm{IC}_{50}$ for mammalian cells and MIC for fungi, was calculated. This index is a measure of the efficacy of a compound against fungus without causing damage to host cells. The IS ranged from $>16$ for C. neoformans to $>64$ for $P$. brasiliensis.

\section{MK58911 Did Not Have a Synergic Effect With Antifungal Drugs}

The interaction between MK58911 and amphotericin B or fluconazole drugs was evaluated against $C$. neoformans through the checkerboard test. For both combinations, FIC values of $>0.5$ to $\leq 4$ were found, indicating that the interactions were indifferent.

\section{MK58911 Causes Membrane Damage on Fungal Cells Through Necrosis and Apoptosis}

To test possible cell membrane effects of the peptide, we performed an assay to evaluate membrane integrity through measuring PI influx. C. neoformans cells treated with MK58911 internalized more PI in a concentration-dependent manner over the course of the experiment (Figure 1). After $4 \mathrm{~h}$ of incubation, all the tested concentrations $(1 / 2 \times$ MIC; MIC and $2 \times$ MIC) caused membrane damage to fungal cells at significantly higher levels $(69.9 ; 73.4$ and 82.23 , respectively) compared to non-treated cells $(20.4$; control with $p<0.05)$, and the treatment with amphotericin B at MIC (41.3), followed with fluconazole at MIC (35.5; Figures 1A,C-F). In contrast, after $24 \mathrm{~h}$, MK58911 at $2 \times$ MIC (30.4) and fluconazole (43.0) showed significantly more PI influx compared to the control (6.3; Figure 1B).

The effect of MK58911 on C. neoformans cell death was also evaluated through measuring apoptosis and necrosis with annexin $\mathrm{V}$ and PI staining. After $4 \mathrm{~h}$, the percentage of apoptotic cells was inversely proportional to the peptide concentration, while the percentage of necrotic cells was directly proportional to the peptide concentration (Figures 2A,B; $p<$ 
TABLE 1 | Minimal inhibitory concentration (MIC in $\mu \mathrm{g} / \mathrm{mL}$ ) for Cryptococcus and Paracoccidioides species, half maximal inhibitory concentration (IC ${ }_{50}$ in $\mu \mathrm{g} / \mathrm{mL}$ ) in MRC5 cell line (lung fibroblasts) and U87 cell line (glioblastoma), and selectivity index (SI) of MK58911.

\begin{tabular}{|c|c|c|c|c|}
\hline & MK58911 & Amphotericin B & Fluconazole & Itraconazole \\
\hline C. neoformans & 31.2 & 0.12 & 1 & - \\
\hline C. gattii & 15.6 & 0.12 & 8 & - \\
\hline P. brasiliensis & 7.8 & 0.12 & - & 0.008 \\
\hline P. lutzii & 15.6 & 0.25 & - & 0.008 \\
\hline $\mathrm{IC}_{50}-\mathrm{MRC5}$ & $>500$ & - & - & - \\
\hline $\mathrm{IC}_{50}-\mathrm{U} 87$ & $>500$ & - & - & - \\
\hline $\mathrm{SI}\left(\mathrm{IC}_{50} / \mathrm{MIC}\right)$ & $>16^{\star}$ & - & - & - \\
\hline
\end{tabular}

*Related to C. neoformans.

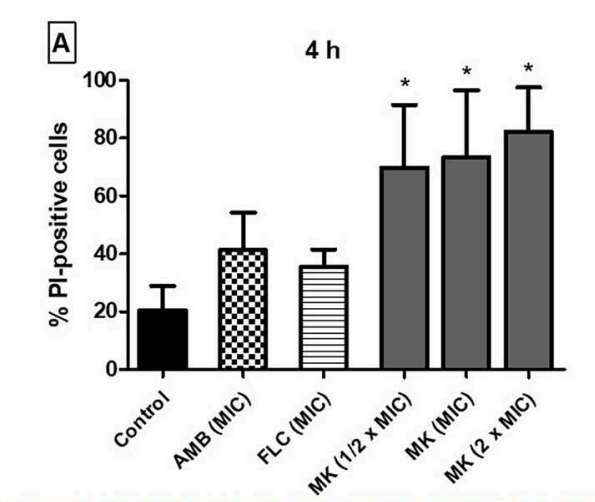

B $\quad 24 \mathrm{~h}$
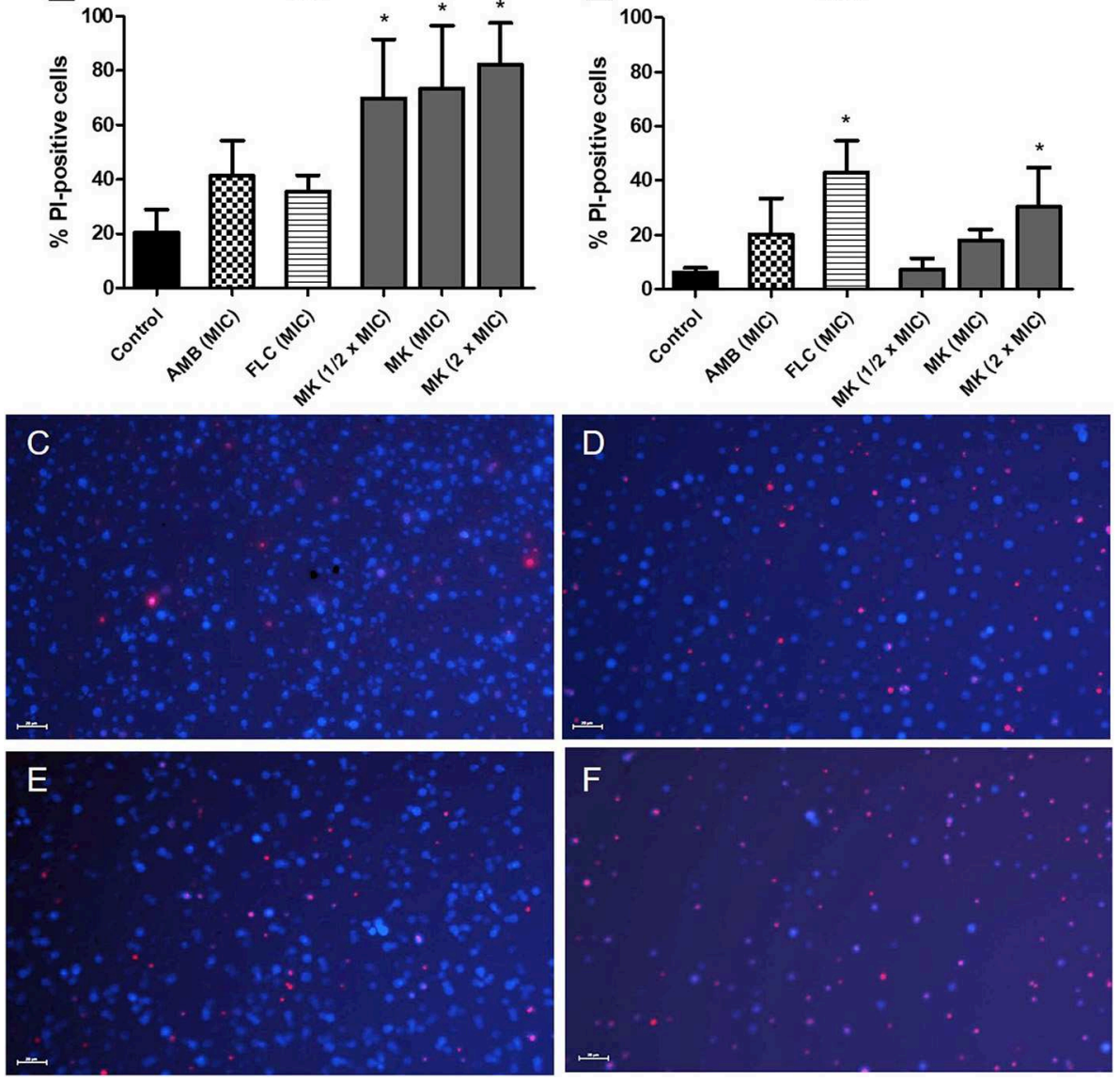

FIGURE 1 | Effect of different concentrations of MK58911 (MK - 1/2 × MIC; MIC and $2 \times$ MIC), amphotericin B (AMB-MIC), or fluconazole (FLC-MIC) on C. neoformans membrane, evaluated by percentage of propidium iodide (PI)-positive cells at (A) $4 \mathrm{~h}$ and (B) $24 \mathrm{~h}$. ${ }^{*} p<0.05$ compared to control group. Representative images of C. neoformans (C) non-treated cells or (D) cells treated at MIC of amphotericin B (E) MIC of fluconazole or (F) MIC of MK58911 at 4 h. The cell wall of all fungal cells was stained with calcofluor (blue), and cells with membrane damage were stained with propidium iodide (red). Scale bar: $20 \mu \mathrm{m}$.

0.05 compared to control). In addition, there was an increase in the percentage of necrotic cells treated with amphotericin B (Figure 3B; $p<0.05$ compared to control), and no significant differences were observed between cells treated with fluconazole and the control (Figures 2A,B). After 24h, the peptide caused an increase in the percentage of apoptotic cells at all concentrations tested (Figure 2C; $p<0.05$ compared to control). Cells treated with amphotericin B (MIC) had a higher percentage of apoptotic events (Figure 2C; $p<0.05$ compared to control), and those treated with fluconazole (MIC) had the most necrotic events (Figure 2D; $p<0.05$ compared to control). 


\section{MK58911 Does Not Lead to ROS Production in C. neoformans}

Since action of the peptide was more pronounced at $4 \mathrm{~h}$ compared to $24 \mathrm{~h}$, we tested its effect on ROS production in fungal cells at this time point. For this purpose, H2DCFDA was used, which is hydrolyzed by esterases inside of cells to $2^{\prime}, 7^{\prime}$ dichlorofluorescine. When this compound contacts ROS, $2^{\prime}, 7^{\prime}$ dichlorofluorescein (DCF) is generated, which is fluorescent. As shown in Figure 3, the mean fluorescence values (1.7-3.0\%) of $C$. neoformans cells were not increased at different concentrations of MK58911 ( $1 / 2 \times$ MIC, MIC, and $2 \times$ MIC) compared to the control (3.1\%), suggesting that the induction of ROS is not a mechanism of action for this peptide. Similarly, ROS production was not observed when fungal cells were exposed to the MIC of fluconazole (4.3\%). On the other hand, amphotericin B at MIC and $2 \times$ MIC lead to an increase in ROS levels in a concentrationdependent manner, with mean values of 12.4 and $25.8 \%$ ( $p<$ 0.05 compared to the control), respectively. $\mathrm{H}_{2} \mathrm{O}_{2}$, a compound known to generate ROS, was tested at a concentration of $5 \mathrm{mM}$, and significantly increased fluorescence $(59.5 \%)$ of C. neoformans cells compared to the control $(p<0.05)$.

\section{MK58911 Has Antifungal Efficacy and No Toxicity When Tested in vivo}

In order to evaluate in vivo effects of MK58911 on C. neoformans, we used a G. mellonella animal model. MK58911 at 10, 50, or 100 $\mathrm{mg} / \mathrm{Kg}$ were administered to non-infected larvae to determine toxicity. No death and melanization in larvae treated with each dose of peptide was observed compared to the control, where PBS was administered (data not shown).

Larvae infected with C. neoformans were treated with the same doses of MK58911 (10, 50, and $100 \mathrm{mg} / \mathrm{Kg}$ ) to evaluate peptide efficacy. Larvae infected with $1 \times 10^{5}$ cells $/ \mathrm{mL}$ of fungus showed a high death rate, mainly occurring on the third day (Figure 4A). All concentrations of MK58911 tested had a similar therapeutic effect in the infected larvae, significantly delaying larvae mortality, with percentage of larvae survival to $\sim 26,29$, and $23 \%$, respectively, compared to the non-treated group $(10 \%$, $p<0.05)$ on the third day. When survival rates for the standard drug amphotericin $B(4 \mathrm{mg} / \mathrm{Kg})$ were measured, we observed a significant delay in larvae mortality, with percentage of larvae survival to $\sim 39 \%(p<0.01)$. We also verified the treatment efficacy for MK58911 given in combination with standard drugs.

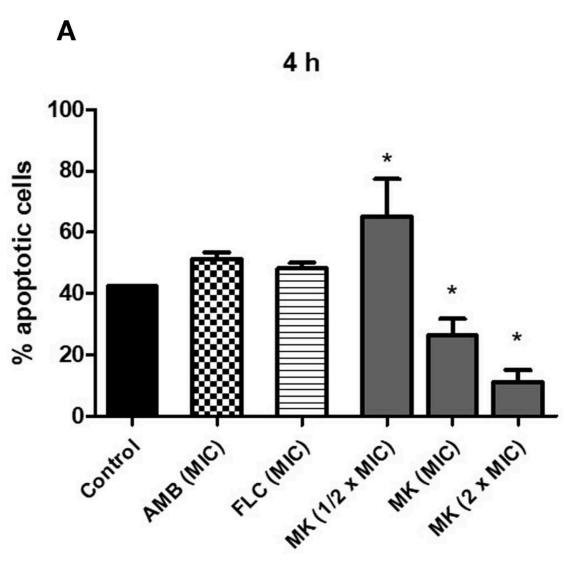

B
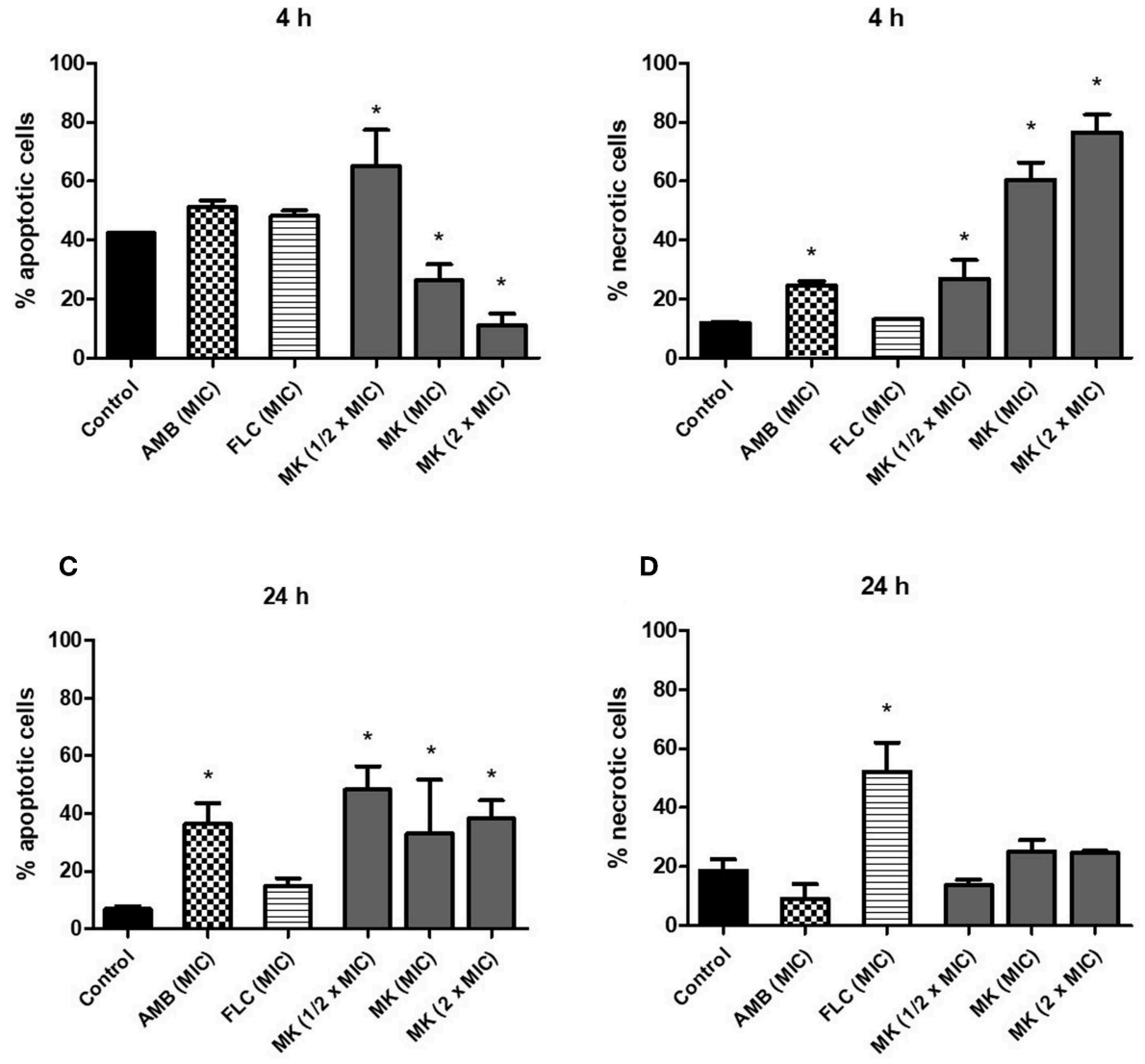

D

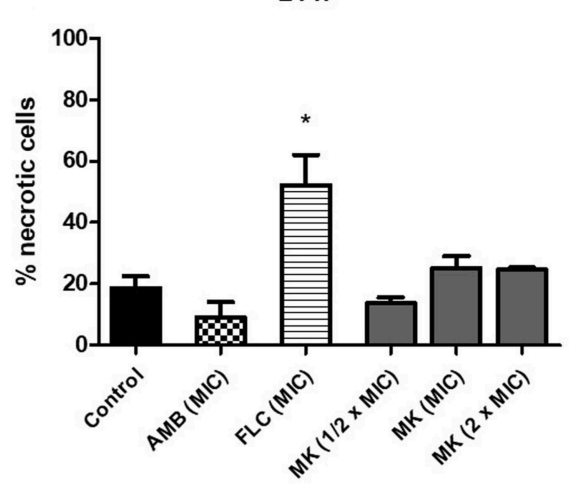

FIGURE 2 | Effect of different concentrations of MK58911 (1/2 × MIC, MIC, and $2 \times \mathrm{MIC}$ ), amphotericin B (MIC), or fluconazole (MIC) on C. neoformans death by apoptosis and necrosis at (A,B) $4 \mathrm{~h}$ and $(\mathbf{C}, \mathbf{D}) 24 \mathrm{~h}$. ${ }^{*} \mathrm{p}<0.05$ compared to control group. 


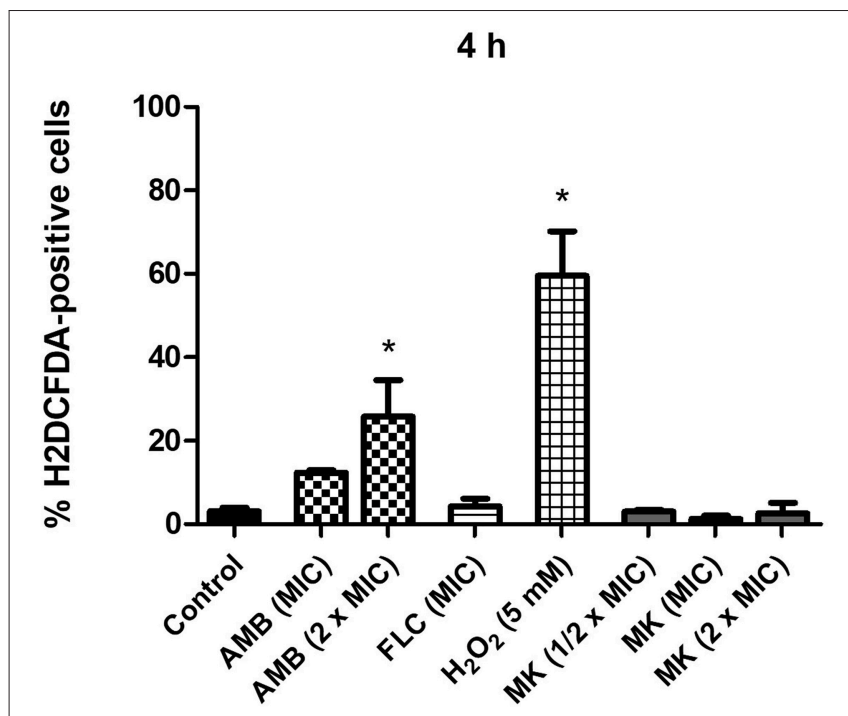

FIGURE 3 | Effect of different concentrations of MK58911 (1/2 × MIC, MIC, and $2 \times \mathrm{MIC})$, amphotericin $\mathrm{B}(\mathrm{MIC})$, or fluconazole $(\mathrm{MIC})$ on induction of oxidative stress in $C$. neoformans at $4 \mathrm{~h}$. ${ }^{\star} p<0.05$ compared to control group.

Since no difference in peptide response at the tested doses was observed in the $G$. mellonella model, we selected a dose of $10 \mathrm{mg} / \mathrm{Kg}$ to perform these experiments. The survival of larvae treated with the combination MK58911 $10 \mathrm{mg} / \mathrm{Kg}+$ amphotericin B $4 \mathrm{mg} / \mathrm{Kg}$ or MK58911 $10 \mathrm{mg} / \mathrm{Kg}$ + fluconazole 10 $\mathrm{mg} / \mathrm{Kg}$ was not significantly different with that of larvae treated solely with amphotericin B or fluconazole.

Furthermore, we evaluated the effect of MK58911 on fungal burden in G. mellonella after $24 \mathrm{~h}$ of treatment. For PBS-treated larvae, the CFU increased after $24 \mathrm{~h}$ compared to administered inoculum $\left(4.9 \times 10^{5}\right.$ vs. $1 \times 10^{5} \mathrm{CFU} /$ larva) (Figure 4B). Although not statistically significant, treatment of larvae with all doses of MK58911 showed a similar trend in decreasing the number of CFU/larva by $\sim 2$-fold compared to control group (2.4 $\times 10^{5}$ vs. $4.9 \times 10^{5} \mathrm{CFU} /$ larva). Amphotericin B significantly reduced the fungal burden by around 13 -fold compared to the control group $\left(3.7 \times 10^{4}\right.$ vs. $4.9 \times 10^{5}$ CFU/larva, $\left.p<0.01\right)$.

\section{MK58911 Did Not Have an Effect on Haemocyte Density}

To investigate whether administration of MK58911 could stimulate an immune response aside from its antifungal activity, the ability of this peptide to alter haemocyte density was determined after 4 or $24 \mathrm{~h}$ of treatment. MK58911 did not alter the number of haemocytes in the larvae hemolymph, and no significant differences were observed between haemocyte density in the peptide-treated and control groups for both evaluated time points (Figures 5A,B).

\section{DISCUSSION}

AMPs of the mastoparan class, isolated from wasp venom, have broad-spectrum activity with both antimicrobial and antitumor properties. Previous studies have demonstrated that this peptide

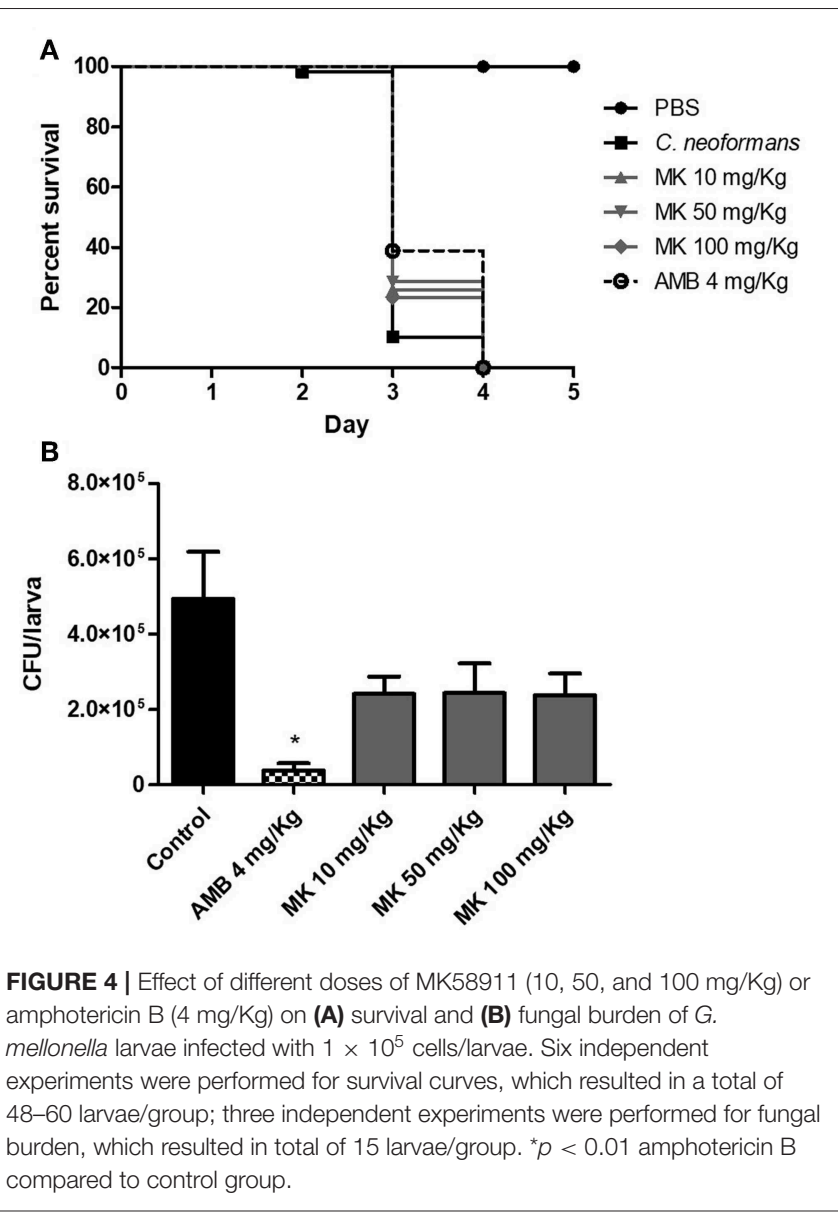

class has activity against Gram-positive and Gram-negative bacteria (Souza et al., 2015). Another mastoparan peptide known as Polybia-MPII was active against $C$. neoformans with an $\mathrm{EC}_{50}$ of $17.7 \mu \mathrm{g} / \mathrm{mL}$ and $\mathrm{EC}_{90}$ of $36.6 \mu \mathrm{g} / \mathrm{mL}$ (Silva et al., 2017). Our results demonstrated that the peptide MK58911 exhibited activity against Cryptococcus and Paracoccidioides species, with MIC values ranging from 7.8 to $31.2 \mu \mathrm{g} / \mathrm{mL}$ (Table 1), denoting a potent antifungal activity.

The SI value is an important consideration in the development of new antimicrobial agents, since it evaluates the ratio between safety and potency. MK58911 was not toxic in lung and neural cells at tested concentrations and had an $\mathrm{IC}_{50}$ of $>500 \mu \mathrm{g} / \mathrm{mL}$ for both mammalian cells (Table 1). Thus, this peptide demonstrated an effective SI value ( $>16)$. According to previous studies, a compound with an SI equal to or greater than 10 may be highly specific (Vicente et al., 2009; Ochoa-Pacheco et al., 2017).

We also tested a combination of two standard antifungals mixed at varying concentrations with the peptide MK58911. This methodology of combining antifungal agents presents several advantages, such as a greater spectrum of activity and potency and a reduction in toxicity, thus improving safety and possibly decreasing the development of resistance. The checkerboard method can be applied in the case where combining two compounds may result in a complementary mechanism of 

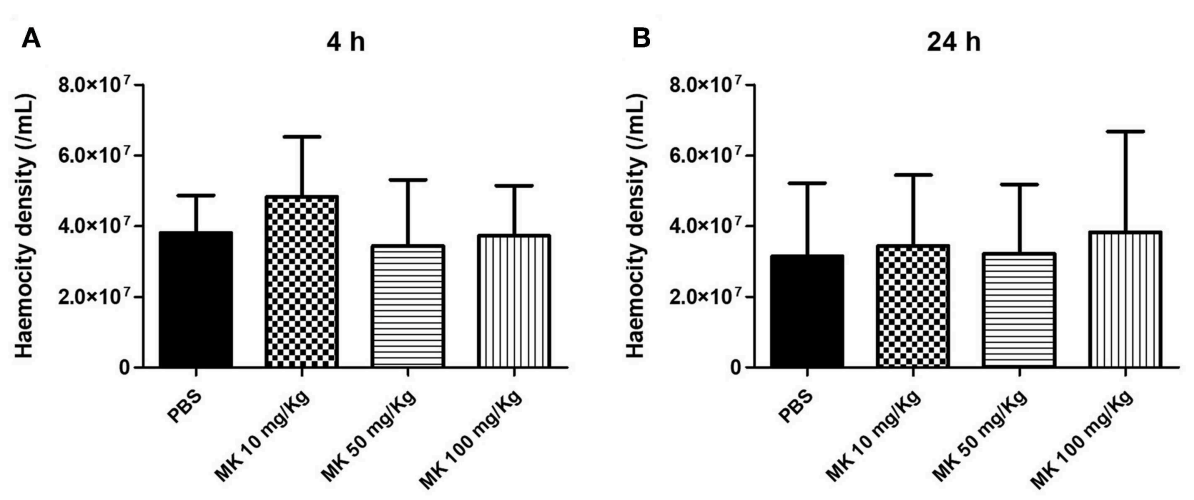

FIGURE 5 | Effect of different doses of MK58911 (10, 50, and $100 \mathrm{mg} / \mathrm{Kg}$ ) on haemocity density of G. mellonella larvae at (A) $4 \mathrm{~h}$ and (B) $24 \mathrm{~h}$. Three independent experiments were performed for haemocity density, which resulted in total of 15 larvae/group.

action (Lewis and Kontoyiannis, 2001; Mukherjee et al., 2005). MK58911 given in combination with amphotericin B or fluconazole demonstrated an indifferent interaction, suggesting that these antifungal drugs and MK58911 have similar targets and/or mechanisms of action. We also evaluated treatment combinations in vivo using the G. mellonella model. However, neither the MK58911 $(10 \mathrm{mg} / \mathrm{Kg})+$ amphotericin B $(4 \mathrm{mg} / \mathrm{Kg})$ combination nor the MK58911 $(10 \mathrm{mg} / \mathrm{Kg})+$ fluconazole $(10$ $\mathrm{mg} / \mathrm{Kg}$ ) combination had a synergic effect on larvae infected with C. neoformans.

Antifungal peptides work through a variety of mechanisms, such as inhibiting attachment to the external cell wall or membrane, forming pores in the lipid bilayer, or through receptor binding. In addition, other peptides lead to the production of reactive oxygen species and apoptosis through activation of signaling cascades or intracellular receptor binding (van der Weerden et al., 2013). A previous study showed that MK58911 interacts with a membrane-mimetic system (Souza et al., 2015). Thus, we decided to use a propidium iodide influx assay to investigate whether this action also occurs on the fungal cell membrane. When a compound is able to damage the membrane by altering its permeability, propidium iodide migrates into the cell and intercalates with the nucleotide bases of fungal deoxyribonucleic acid (DNA), turning the cell fluorescent (Choi and Lee, 2014).

When we tested the MIC as well as higher and lower concentrations $(0.5 \times$ MIC and $2 \times$ MIC), we found that MK58911 has potent activity in the membrane integrity of C. neoformans (Figure 1). More activity occurred at $4 \mathrm{~h}$ when compared to $24 \mathrm{~h}$, and the efficacy of this compound was higher than that of the drugs currently used for treating cryptococcosis (amphotericin B and fluconazole). In addition, MK58911 also showed concentration-dependent activity. Amphotericin $B$ had the best effect at $4 \mathrm{~h}$, since its mechanism of action involves binding directly to ergosterol and increasing membrane permeability, leading to rapid fungal death. On the other hand, fluconazole showed the highest membrane activity at $24 \mathrm{~h}$, since its mechanism of action involves blocking ergosterol synthesis, a slower process (Odds et al., 2003; Scorzoni et al., 2017).
MK58911 works rapidly and directly on the membrane, unlike the other antifungal drugs. We hypothesize that mastoparan peptides are interacting with phospholipids of cell membranes through the "carpet" mechanism, which leads to pore formation and, subsequently, to cytolysis (da Silva et al., 2014). However, further studies are necessary to investigate this hypothesis related to MK58911.

We also evaluated if the membrane damage caused by MK58911 exposure was due to fungal death by apoptosis or necrosis, which were measured by annexin V and PI staining. Annexin V has a high affinity for phosphatidylserine, a main component of the lipid bilayer inner surface. When apoptosis is initiated, a rapid exposure of phosphatidylserine to the outer bilayer surface occurs, which leads to recognition by annexin V. Additionally, an influx of propidium iodide occurs in cells undergoing necrosis or late apoptosis (Sharon et al., 2009). We could therefore distinguish apoptosis and necrosis through the use of annexin V and PI with flow cytometry (Crowley et al., 2016).

At $4 \mathrm{~h}$, MK58911 appears to promote necrosis as the main effect, since these effects were significant and concentration dependent (Figure 2). At $24 \mathrm{~h}$, an increase in apoptotic cells was observed compared to control. Similarly, amphotericin B induced necrotic events initially and apoptotic events later, which has also been seen in previous studies (Phillips et al., 2003; Mousavi and Robson, 2004). On the other hand, fluconazole caused a significant percentage of necrotic events compared to the control at $24 \mathrm{~h}$, when the highest membrane damage was also observed.

The production of ROS is a known trigger in the cell death cascade. The pro-oxidant activity of ROS leads to an imbalance in stationary state of the cell, promoting so-called oxidative stress. This imbalance results in damage to biomolecules, such as DNA, lipids, proteins, and carbohydrates, which interfere with cell survival, death, and proliferation (Circu and Aw, 2010; Delattin et al., 2014). Thus, the increase of ROS in fungal cells may be responsible for a series of intracellular events that result in different types of cell death. In addition to promoting membrane damage, some antimicrobial peptides induce ROS 
accumulation, leading to fungal cell death (De Brucker et al., 2011; Hwang et al., 2011; Delattin et al., 2014). Because of this, we also investigated the action of MK58911 on ROS production. However, exposure to MK58911 for $4 \mathrm{~h}$ had no significant effect on oxidative stress in C. neoformans cells (Figure 3). In the same way, we observed no significant differences between fluconazoletreated cells and the control group, which is supported by a previous study (Ferreira et al., 2013). In contrast, amphotericin $\mathrm{B}$ exposure resulted in a concentration-dependent increase on the production of ROS. This event causes an initial oxidative burst and can also contribute to damage of the C. neoformans cell membrane through oxidation of membrane lipids (Sangalli-Leite et al., 2011).

Recently, G. mellonella have been used to investigate fungal pathogenesis as well as toxicity and efficacy of antifungal agents. These larvae have additional benefits compared to others invertebrate models, such as an incubation temperature of $37^{\circ} \mathrm{C}$, which mimics infection conditions in mammals, and precise concentrations of pathogens and antimicrobial drugs can be administered to the prolegs (Fuchs and Mylonakis, 2006; Desalermos et al., 2012; Arvanitis et al., 2013). On the other hand, the use of G. mellonella, as with any model organism, has some drawbacks. Some systems/organs related to infection (adaptative immune system, lung, nervous central system) are absent or not easily comparable to those of mammals. In addition, the lack of standardized and mutant strains of G. mellonella may limit reproducibility of methods and dissemination of the model, but its recent genome sequencing can solve these problems (Binder et al., 2016; Lange et al., 2018)

In this study, MK58911 administered at doses of up to 100fold the MIC did not result in toxic effects, such as death or melanization in G. mellonella larvae, which is similar to what was seen in lung and neural cells. Amphotericin at a concentration as high as $4 \mathrm{mg} / \mathrm{Kg}$ has been tested in the $G$. mellonella model with no toxicity, according to previous studies from our group (de Lacorte Singulani et al., 2016; Sangalli-Leite et al., 2016). In addition, MK58911 was effective in larvae infected with $C$. neoformans, and a significant delay in larvae mortality was observed with all doses of peptide treatment $(p<0.05$, Figure 4). These effects were not dose-dependent, and a possible explanation is that the peptide is either being metabolized or is forming a complex with components of haemolymph, thus limiting activity at higher doses (Gibreel and Upton, 2013). However, low doses were sufficient for achieving an in vivo antifungal activity.

Several features of the innate immune response are conserved between insects and mammals. For instance, G. mellonella has six important cell types, or haemocytes, in its defense system.

\section{REFERENCES}

Arantes, T. D., Theodoro, R. C., Teixeira M. de M., Bosco S. de M., and Bagagli, E. (2016). Environmental mapping of Paracoccidioides spp. in Brazil reveals new clues into genetic diversity, biogeography and wild host association. PLoS Negl. Trop. Dis. 10:0004606. doi: 10.1371/journal.pntd.0004606
Specifically, haemocytes that are plasmatocytes or granulocytes have key roles in microbial defense, including phagocytosis, nodule formation, and encapsulation of microorganisms (Tojo et al., 2000). Thus, a fluctuation in haemocyte density in the hemolymph is observed based on the pathogenicity of the fungus (Bergin et al., 2003; Scorzoni et al., 2015; de Lacorte Singulani et al., 2016). In addition, some antifungals, such as lipopeptides, caspofungin, and micafungin cause a significant increase in the number of haemocytes in the G. mellonella model (Kelly and Kavanagh, 2011; Fuchs et al., 2015). We also evaluated if therapeutic effects of MK58911 on larvae could be related to a variation in haemocyte density. However, there were no significant differences between haemocyte density in the groups treated with each concentration of MK58911 and the control group (Figure 5).

\section{CONCLUSION}

In conclusion, MK58911 is not toxic in two mammalian cells (lung fibroblasts and glioblastoma cells) and in the G. mellonella model and demonstrates both in vitro and in vivo antifungal efficacy. Moreover, the peptide acted on the membrane of fungal cells and induced necrosis. These results are promising, and further studies should determine whether similar results can be obtained in a murine model. Finally, MK58911 can be used as an example in the rational design of peptide analogs as a new class of antifungal agents.

\section{DATA AVAILABILITY STATEMENT}

The datasets generated for this study are included in the manuscript.

\section{AUTHOR CONTRIBUTIONS}

JS and MM contributed to the research idea and experimental design. JS, MG, MR, and CS performed the experiments. PG, BS, and MP synthesized the peptide. JS, MG, MR, and CS analyzed the data. JS, MG, and MR prepared and wrote the manuscript. PG, CS, MP, AF, and MM revised the final draft of manuscript.

\section{FUNDING}

This study was supported by the Fundação de Amparo à Pesquisa do Estado de São Paulo (FAPESP grants no. 2017/06658-9 and 2016/16212-5) and Coordenação de Aperfeiçoamento de Pessoal de Nível Superior-Brasil (CAPES). epidemic: fungal infections in HIV/AIDS. Trends Microbiol. 22, 120-127. doi: 10.1016/j.tim.2014.01.001

Arvanitis, M., Glavis-Bloom, J., and Mylonakis, E. (2013). Invertebrate models of fungal infection. Biochim. Biophys. Acta 1832, 1378-1383. doi: 10.1016/j.bbadis.2013.03.008 
Bergin, D., Brennan, M., and Kavanagh, K. (2003). Fluctuations in haemocyte density and microbial load may be used as indicators of fungal pathogenicity in larvae of Galleria mellonella. Microbes Infect. 5, 1389-1395. doi: 10.1016/j.micinf.2003.09.019

Binder, U., Maurer, E., and Lass-Florl, C. (2016). Galleria mellonella: an invertebrate model to study pathogenicity in correctly defined fungal species. Fungal Biol. 120, 288-295. doi: 10.1016/j.funbio.2015.06.002

Brown, G. D., Denning, D. W., Gow, N. A., Levitz, S. M., Netea, M. G., and White, T. C. (2012). Hidden killers: human fungal infections. Sci. Transl. Med. 4:165rv13. doi: 10.1126/scitranslmed.3004404

Choi, H., and Lee, D. G. (2014). Antifungal activity and pore-forming mechanism of astacidin 1 against Candida albicans. Biochimie 105, 58-63. doi: 10.1016/j.biochi.2014. 06.014

Circu, M. L., and Aw, T. Y. (2010). Reactive oxygen species, cellular redox systems, and apoptosis. Free Radic. Biol. Med. 48, 749-762. doi: 10.1016/j.freeradbiomed.2009.12.022

Crowley, L. C., Marfell, B. J., Scott, A. P., and Waterhouse, N. J. (2016). Quantitation of apoptosis and necrosis by annexin $\mathrm{V}$ binding, propidium iodide uptake, and flow cytometry. Cold Spring Harb. Protoc. 2016. doi: $10.1101 /$ pdb.prot087288

da Costa, J. P., Cova, M., Ferreira, R., and Vitorino, R. (2015). Antimicrobial peptides: an alternative for innovative medicines? Appl. Microbiol. Biotechnol. 99, 2023-2040. doi: 10.1007/s00253-015-6375-x

da Silva, A. V., De Souza, B. M., Dos Santos Cabrera, M. P., Dias, N. B., Gomes, P. C., Neto, J. R., et al. (2014). The effects of the C-terminal amidation of mastoparans on their biological actions and interactions with membrane-mimetic systems. Biochim. Biophys. Acta 1838, 2357-2368. doi: 10.1016/j.bbamem.2014.06.012

De Brucker, K., Cammue, B. P., and Thevissen, K. (2011). Apoptosis-inducing antifungal peptides and proteins. Biochem. Soc. Trans. 39, 1527-1532. doi: 10.1042/BST0391527

de Lacorte Singulani, J., Scorzoni, L., de Paula E Silva, A. C., Fusco-Almeida, A. M., and Mendes-Giannini, M. J. (2016). Evaluation of the efficacy of antifungal drugs against Paracoccidioides brasiliensis and Paracoccidioides lutzii in a Galleria mellonella model. Int. J. Antimicrob. Agents 48, 292-297. doi: 10.1016/j.ijantimicag.2016.05.012

de Oliveira, H. C., Assato, P. A., Marcos, C. M., Scorzoni, L., de Paula E Silva, A. C., Da Silva J. de F., et al. (2015). Paracoccidioides-host interaction: an overview on recent advances in the paracoccidioidomycosis. Front. Microbiol. 6:1319. doi: 10.3389/fmicb.2015.01319

de Paula E Silva, A. C., Oliveira, H. C., Silva, J. F., Sangalli-Leite, F., Scorzoni, L., Fusco-Almeida, A. M., et al. (2013). Microplate alamarBlue assay for Paracoccidioides susceptibility testing. J. Clin. Microbiol. 51, 1250-1252. doi: 10.1128/JCM.02914-12

Delattin, N., Cammue, B. P., and Thevissen, K. (2014). Reactive oxygen speciesinducing antifungal agents and their activity against fungal biofilms. Future Med. Chem. 6, 77-90. doi: 10.4155/fmc.13.189

Denning, D. W. (2002). Echinocandins: a new class of antifungal. J. Antimicrob. Chemother. 49, 889-891. doi: 10.1093/jac/dkf045

Desalermos, A., Fuchs, B. B., and Mylonakis, E. (2012). Selecting an invertebrate model host for the study of fungal pathogenesis. PLoS Pathog. 8:e1002451. doi: 10.1371/journal.ppat.1002451

Favre-Godal, Q., Dorsaz, S., Queiroz, E. F., Conan, C., Marcourt, L., Wardojo, B. P., et al. (2014). Comprehensive approach for the detection of antifungal compounds using a susceptible strain of Candida albicans and confirmation of in vivo activity with the Galleria mellonella model. Phytochemistry 105, 68-78. doi: 10.1016/j.phytochem.2014.06.004

Ferreira, G. F., Baltazar Lde, M., Santos, J. R., Monteiro, A. S., Fraga, L. A., ResendeStoianoff, M. A., et al. (2013). The role of oxidative and nitrosative bursts caused by azoles and amphotericin B against the fungal pathogen Cryptococcus gattii. J. Antimicrob. Chemother. 68, 1801-1811. doi: 10.1093/jac/dkt114

Fuchs, B. B., Li, Y., Li, D., Johnston, T., Hendricks, G., Li, G., et al. (2015). Micafungin elicits an immunomodulatory effect in Galleria mellonella and mice. Mycopathologia 181, 17-25. doi: 10.1007/s11046-015-9940-z

Fuchs, B. B., and Mylonakis, E. (2006). Using non-mammalian hosts to study fungal virulence and host defense. Curr. Opin. Microbiol. 9, 346-351. doi: 10.1016/j.mib.2006.06.004
Fuchs, B. B., O’Brien, E., Khoury, J. B., and Mylonakis, E. (2010). Methods for using Galleria mellonella as a model host to study fungal pathogenesis. Virulence 1, 475-482. doi: 10.4161/viru.1.6.12985

Garcia-Effron, G., Lee, S., Park, S., Cleary, J. D., and Perlin, D. S. (2009). Effect of Candida glabrata FKS1 and FKS2 mutations on echinocandin sensitivity and kinetics of 1,3-beta-D-glucan synthase: implication for the existing susceptibility breakpoint. Antimicrob. Agents Chemother. 53, 3690-3699. doi: 10.1128/AAC.00443-09

Gibreel, T. M., and Upton, M. (2013). Synthetic epidermicin NI01 can protect Galleria mellonella larvae from infection with Staphylococcus aureus. J. Antimicrob. Chemother. 68, 2269-2273. doi: 10.1093/jac/dkt195

Haney, E. F., Mansour, S. C., and Hancock, R. E. (2017). Antimicrobial peptides: an introduction. Methods Mol. Biol. 1548, 3-22. doi: 10.1007/978-1-4939-6737-7_1

Hwang, B., Hwang, J. S., Lee, J., and Lee, D. G. (2011). The antimicrobial peptide, psacotheasin induces reactive oxygen species and triggers apoptosis in Candida albicans. Biochem. Biophys. Res. Commun. 405, 267-271. doi: 10.1016/j.bbrc.2011.01.026

Kang, H. K., Kim, C., Seo, C. H., and Park, Y. (2017). The therapeutic applications of antimicrobial peptides (AMPs): a patent review. J. Microbiol. 55, 1-12. doi: 10.1007/s12275-017-6452-1

Kavanagh, K., and Sheehan, G. (2018). The use of Galleria mellonella larvae to identify novel antimicrobial agents against fungal species of medical interest. J. Fungi 4:E113. doi: 10.3390/jof4030113

Kelly, J., and Kavanagh, K. (2011). Caspofungin primes the immune response of the larvae of Galleria mellonella and induces a non-specific antimicrobial response. J. Med. Microbiol. 60, 189-196. doi: 10.1099/jmm.0.025494-0

Lange, A., Beier, S., Huson, D. H., Parusel, R., Iglauer, F., and Frick, J. S. (2018). Genome sequence of Galleria mellonella (greater wax moth). Genome Announc. 6:e01220-17. doi: 10.1128/genomeA.01220-17

Lewis, R. E., and Kontoyiannis, D. P. (2001). Rationale for combination antifungal therapy. Pharmacotherapy 21, 149S-164S. doi: 10.1592/phco.21.12.149S.34505

Mourad, A., and Perfect, J. R. (2018). The war on cryptococcosis: a review of the antifungal arsenal. Mem. Inst. Oswaldo Cruz 113:e170391. doi: 10.1590/0074-02760170391

Mousavi, S. A., and Robson, G. D. (2004). Oxidative and amphotericin Bmediated cell death in the opportunistic pathogen Aspergillus fumigatus is associated with an apoptotic-like phenotype. Microbiology 150, 1937-1945. doi: 10.1099/mic.0.26830-0

Mukherjee, P. K., Sheehan, D. J., Hitchcock, C. A., and Ghannoum, M. A. (2005). Combination treatment of invasive fungal infections. Clin. Microbiol. Rev. 18, 163-194. doi: 10.1128/CMR.18.1.163-194.2005

Mylonakis, E., Moreno, R., El Khoury, J. B., Idnurm, A., Heitman, J., Calderwood, S. B., et al. (2005). Galleria mellonella as a model system to study Cryptococcus neoformans pathogenesis. Infect. Immun. 73, 3842-3850. doi: 10.1128/IAI.73.7.3842-3850.2005

Ochoa-Pacheco, A., Escalona Arranz, J. C., Beaven, M., Peres-Roses, R., Gamez, Y. M., Camacho-Pozo, M. I., et al. (2017). Bioassay-guided in vitro study of the antimicrobial and cytotoxic properties of the leaves from Excoecaria lucida Sw. Pharmacogn. Res. 9, 396-400. doi: 10.4103/pr.pr_124_16

Odds, F. C., Brown, A. J., and Gow, N. A. (2003). Antifungal agents: mechanisms of action. Trends Microbiol. 11, 272-279. doi: 10.1016/S0966-842X(03)00117-3

Palanco, A. C., Lacorte Singulani, J., Costa-Orlandi, C. B., Gullo, F. P., Strohmayer Lourencetti, N. M., Gomes, P. C., et al. (2017). Activity of 3 '-hydroxychalcone against Cryptococcus gattii and toxicity, and efficacy in alternative animal models. Future Microbiol. 12, 1123-1134. doi: 10.2217/fmb-2017-0062

Perfect, J. R. (2017). The antifungal pipeline: a reality check. Nat. Rev. Drug Discov. 16, 603-616. doi: 10.1038/nrd.2017.46

Perlin, D. S. (2015). Mechanisms of echinocandin antifungal drug resistance. Ann. N. Y. Acad. Sci. 1354, 1-11. doi: 10.1111/nyas.12831

Phillips, A. J., Sudbery, I., and Ramsdale, M. (2003). Apoptosis induced by environmental stresses and amphotericin B in Candida albicans. Proc. Natl. Acad. Sci. U.S.A. 100, 14327-14332. doi: 10.1073/pnas.2332326100

Prasad, R., Shah, A. H., and Rawal, M. K. (2016). Antifungals: mechanism of action and drug resistance. Adv. Exp. Med. Biol. 892, 327-349. doi: 10.1007/978-3-319-25304-6_14

Rajasingham, R., Smith, R. M., Park, B. J., Jarvis, J. N., Govender, N. P., Chiller, T. M., et al. (2017). Global burden of disease of HIV-associated 
cryptococcal meningitis: an updated analysis. Lancet Infect. Dis. 17, 873-881. doi: 10.1016/S1473-3099(17)30243-8

Rangel, M., Cabrera, M. P., Kazuma, K., Ando, K., Wang, X., Kato, M., et al. (2011). Chemical and biological characterization of four new linear cationic alphahelical peptides from the venoms of two solitary eumenine wasps. Toxicon 57, 1081-1092. doi: 10.1016/j.toxicon.2011.04.014

Rautenbach, M., Troskie, A. M., and Vosloo, J. A. (2016). Antifungal peptides: to be or not to be membrane active. Biochimie 130, 132-145. doi: 10.1016/j.biochi.2016.05.013

Reichert-Lima, F., Busso-Lopes, A. F., Lyra, L., Peron, I. H., Taguchi, H., Mikami, Y., et al. (2016). Evaluation of antifungal combination against Cryptococcus spp. Mycoses 59, 585-593. doi: 10.1111/myc. 12510

Sangalli-Leite, F., Scorzoni, L., Alves de Paula E Silva, A. C., da Silva, J. F., de Oliveira, H. C., de Lacorte Singulani, J., et al. (2016). Synergistic effect of pedalitin and amphotericin B against Cryptococcus neoformans by in vitro and in vivo evaluation. Int. J. Antimicrob. Agents 48, 504-511. doi: 10.1016/j.ijantimicag.2016.07.025

Sangalli-Leite, F., Scorzoni, L., Mesa-Arango, A. C., Casas, C., Herrero, E., Gianinni, M. J., et al. (2011). Amphotericin B mediates killing in Cryptococcus neoformans through the induction of a strong oxidative burst. Microbes Infect. 13, 457-467. doi: 10.1016/j.micinf.2011.01.015

Scorzoni, L., de Lucas, M. P., Mesa-Arango, A. C., Fusco-Almeida, A. M., Lozano, E., Cuenca-Estrella, M., et al. (2013). Antifungal efficacy during Candida krusei infection in non-conventional models correlates with the yeast in vitro susceptibility profile. PLoS ONE 8:e60047. doi: 10.1371/journal.pone.0060047

Scorzoni, L., de Paula E Silva, A. C., Marcos, C. M., Assato, P. A., de Melo, W. C., de Oliveira, H. C., et al. (2017). Antifungal therapy: new advances in the understanding and treatment of mycosis. Front. Microbiol. 8:36. doi: $10.3389 /$ fmicb.2017.00036

Scorzoni, L., de Paula E Silva, A. C., Singulani, J. L., Leite, F. S., de Oliveira, H. C., Moraes da Silva, R. A., et al. (2015). Comparison of virulence between Paracoccidioides brasiliensis and Paracoccidioides lutzii using Galleria mellonella as a host model. Virulence, 1-11. doi: 10.1080/21505594.2015.1085277

Sharon, A., Finkelstein, A., Shlezinger, N., and Hatam, I. (2009). Fungal apoptosis: function, genes and gene function. FEMS Microbiol. Rev. 33, 833-854. doi: 10.1111/j.1574-6976.2009.00180.x

Shikanai-Yasuda, M. A., Mendes, R. P., Colombo, A. L., Queiroz-Telles, F., Kono, A. S. G., Paniago, A. M. M., et al. (2017). Brazilian guidelines for the clinical management of paracoccidioidomycosis. Rev. Soc. Bras. Med. Trop. 50, 715-740. doi: 10.1590/0037-8682-0230-2017

Shikanai-Yasuda, M. A., Telles Filho, F. E. Q., Mendes, R. P., Colombo, A. L., and Moretti, M. L. (2006). Guidelines in paracoccidioidomycosis. Rev. Soc. Bras. Med. Trop. 39, 297-310. doi: 10.1590/S0037-86822006000300017

Silva, J. C., Neto, L. M., Neves, R. C., Goncalves, J. C., Trentini, M. M., Mucury-Filho, R., et al. (2017). Evaluation of the antimicrobial activity of the mastoparan Polybia-MPII isolated from venom of the social wasp Pseudopolybia vespiceps testacea (Vespidae, Hymenoptera). Int. J. Antimicrob. Agents 49, 167-175. doi: 10.1016/j.ijantimicag.2016.11.013

Singulani, J. L., Scorzoni, L., de Oliveira, H. C., Marcos, C. M., Assato, P. A., FuscoAlmeida, A. M., et al. (2018). Applications of invertebrate animal models to dimorphic fungal infections. J. Fungi 4:E118. doi: 10.3390/jof4040118
Souza, B. M., Cabrera, M. P., Gomes, P. C., Dias, N. B., Stabeli, R. G., Leite, N. B., et al. (2015). Structure-activity relationship of mastoparan analogs: effects of the number and positioning of Lys residues on secondary structure, interaction with membrane-mimetic systems and biological activity. Peptides 72, 164-174. doi: 10.1016/j.peptides.2015.04.021

Tenor, J. L., Oehlers, S. H., Yang, J. L., Tobin, D. M., and Perfect, J. R. (2015). Live imaging of host-parasite interactions in a zebrafish infection model reveals cryptococcal determinants of virulence and central nervous system invasion. MBio 6:e01425-15. doi: 10.1128/mBio.01425-15

Thomaz, L., García-Rodas, R., Guimarães, A. J., Taborda, C. P., Zaragoza, O., and Nosanchuk, J. D. (2013). Galleria mellonella as a model host to study Paracoccidioides lutzii and Histoplasma capsulatum. Virulence 4, 139-146. doi: 10.4161/viru.23047

Thompson, G. R. III., Rendon, A., Ribeiro Dos Santos, R., Queiroz-Telles, F., Ostrosky-Zeichner, L., Azie, N., et al. (2016). Isavuconazole treatment of cryptococcosis and dimorphic mycoses. Clin. Infect. Dis. 63, 356-362. doi: $10.1093 / \mathrm{cid} / \mathrm{ciw} 305$

Tojo, S., Naganuma, F., Arakawal, K., and Yokoo, S. (2000). Involvement of both granular cells and plasmatocytes in phagocytic reactions in the greater wax moth, Galleria mellonella. J. Insect Physiol. 46, 1129-1135. doi: 10.1016/S0022-1910(99)00223-1

van der Weerden, N. L., Bleackley, M. R., and Anderson, M. A. (2013). Properties and mechanisms of action of naturally occurring antifungal peptides. Cell. Mol. Life Sci. 70, 3545-3570. doi: 10.1007/s00018-013$1260-1$

Vicente, E., Perez-Silanes, S., Lima, L. M., Ancizu, S., Burguete, A., Solano, B., et al. (2009). Selective activity against Mycobacterium tuberculosis of new quinoxaline 1,4-di-N-oxides. Bioorg. Med. Chem. 17, 385-389. doi: 10.1016/j.bmc.2008.10.086

Wang, K., Jia, F., Dang, W., Zhao, Y., Zhu, R., Sun, M., et al. (2016). Antifungal effect and action mechanism of antimicrobial peptide polybia-CP. J. Pept. Sci. 22, 28-35. doi: 10.1002/psc.2835

Yount, N. Y., and Yeaman, M. R. (2012). Emerging themes and therapeutic prospects for anti-infective peptides. Annu. Rev. Pharmacol. Toxicol. 52, 337-360. doi: 10.1146/annurev-pharmtox-010611134535

Zaiou, M. (2007). Multifunctional antimicrobial peptides: therapeutic targets in several human diseases. J. Mol. Med. 85, 317-329. doi: 10.1007/s00109-006-0143-4

Conflict of Interest: The authors declare that the research was conducted in the absence of any commercial or financial relationships that could be construed as a potential conflict of interest.

Copyright (C) 2019 Singulani, Galeane, Ramos, Gomes, dos Santos, de Souza, Palma Fusco Almeida and Mendes Giannini. This is an open-access article distributed under the terms of the Creative Commons Attribution License (CC BY). The use, distribution or reproduction in other forums is permitted, provided the original author(s) and the copyright owner(s) are credited and that the original publication in this journal is cited, in accordance with accepted academic practice. No use, distribution or reproduction is permitted which does not comply with these terms. 